\title{
Preparation and characterization of bio-based polyurethanes obtained from castor oil and poly(3-hydroxybutyrate) and their nanocomposites
}

\author{
Mohamed S. Abdel Aziz, Mahmoud Gebril, Gamal R. Saad* \\ Department of Chemistry, Faculty of Science, Cairo University, 12613, Giza, Egypt
}

\begin{abstract}
Series of polyurethanes (PUs) based on PHB and castor oil CO were prepared using hexamethylene diisocyanate as a coupling agent. Nanocomposites of the prepared PUs were also prepared using cloisite $25 \mathrm{~A}$ as nanofiller with different contents. FTIR an increment in the surface roughness with increasing both PHB and C25A. DSC showed that the samples exhibited two $T_{\mathrm{g}}$ values for both PHB and castor oil. The physical transition temperatures were found to depend on the contents of $\mathrm{PHB}, \mathrm{CO}$ and $\mathrm{C} 25 \mathrm{~A}$. The degradation behavior was studied using thermogravimetric analysis.
\end{abstract}

Keywords: poly(3-hydroxybutyrate); castor oil; polyurethanes; nanoclay; nanocomposites

${ }^{*}$ Corresponding author. Tel.: +20-35676626.

E-mail addresses: grsaad@yahoo.com

\section{Introduction}

Polyurethanes (PUs) are important materials that result from the reaction of a diisocyanate with a polyol. Among renewable polyols, castor oilwhich consists of ricinolein, the hydroxyl groups are uniformly positioned at the 12th carbon in the chain.Properties of PUs based on $\mathrm{CO}$ can be improved throughincorporation of nanofillers asnanoclays to make polymeric nanocomposites (Kaushik, Ahuja et al. 2011, Panda, Samal et al. 2017). The most common nanofillers are organically modified montmorillonite (MMT) or organoclay. The modified organoclays have better interfacial adhesion properties with hydrophobic polymer matrix.

Poly( $\beta$-hydroxybutyrate) (PHB) is bio-based aliphatic polyester madefrom renewable resources through bacterial fermentation. PHB has received a considerable attention owing to its biocompostability, biocompatibility and biodegradability(Naguib, Aziz et al. 2011). However, PHB has not been widely due to its high price, brittleness, poor processability (Aziz, Saad et al. 
2015). The preparation of PUs from PHB and more flexible polymers as (butylene adipate) (Abdel Aziz, Naguib et al. 2014)allows us to hamper PHB drawbacks. The goal of this work was the synthesis of PUs using CO andPHB.Nanocomposites of the prepared PUs and C25A were also prepared. The synthesis was carried out in solution via a one-step polymerization with varying the soft/hard segment ratio. The physical and chemical properties were studied.

\section{Experimental}

\subsection{Materials}

Castor oil (CO) with hydroxyl number $168 \mathrm{mg} \mathrm{KOH} / \mathrm{g}$ and molecular weight $928 \mathrm{~g} \mathrm{~mol}{ }^{-}$

${ }^{1}$ was supplied by Sigma. PHBwas supplied from Biomer®(Krailling, Germany). Dibutyltin dilaurate, 1,6-hexamethylene diisocyanate (HDI) p-toluenesulfonic acid, 1,4-Butanediol and 1,2dichloroethane were purchased from Aldrich. Cloisite ${ }^{\circledR}$ 25Awas supplied from Southern Clay Products. PHB-diolwas prepared according to the method described previously(Reeve, McCarthy et al. 1993).

\subsection{Synthesis of PUs}

Mixture of $\mathrm{CO}$ and PHB-diol were dissolved in 1,2-dicloroethane, then an equivalent amount of HDIin the presence of of dibutyltin dilauratewasallowed to react for $4 \mathrm{~h}$ at $80^{\circ} \mathrm{C}$.Casting in Teflon plate at $90^{\circ} \mathrm{C}$ for $24 \mathrm{~h}$ in an oven was performed. The procedure is shown in scheme 1.The chemical compositions of PUs are given in Table 1.

\subsection{Preparation ofPUs nanocomposites}

$\mathrm{CO}$ and PHB-diol were dissolved in 1,2-dichloroethane and an appropriate amount of C25At was added. An equivalent amount of HDI was added gradually for $4 \mathrm{~h}$. The solution was poured into Teflon plate and placed for 24 h. Sheets containing 3.0, 5.0and 7.0 wt $\%$ C25A were obtained. The composites were coded as $\mathrm{U}(\mathrm{PHB} / \mathrm{CO}) \mathrm{x}-\mathrm{y}$, where $\mathrm{x}$ and $\mathrm{y}$ represents the weight percent of PHB and C25A, respectively.

Table 1 Nomenclature and chemical compositions of the prepared PUs.

\begin{tabular}{llll}
\hline Sample code & PHB (wt\%) & CO (wt \%) & Urethane linkage (wt \%) \\
\hline $\mathrm{U}(\mathrm{CO})$ & - & 81.0 & 19.0 \\
$\mathrm{U}(\mathrm{PHB} / \mathrm{CO})-20$ & 20.0 & 64.0 & 16.0 \\
$\mathrm{U}(\mathrm{PHB} / \mathrm{CO})-40$ & 40.0 & 47.6 & 12.4 \\
$\mathrm{U}(\mathrm{PHB} / \mathrm{CO})-60$ & 60.0 & 31.1 & 8.9 \\
\hline
\end{tabular}




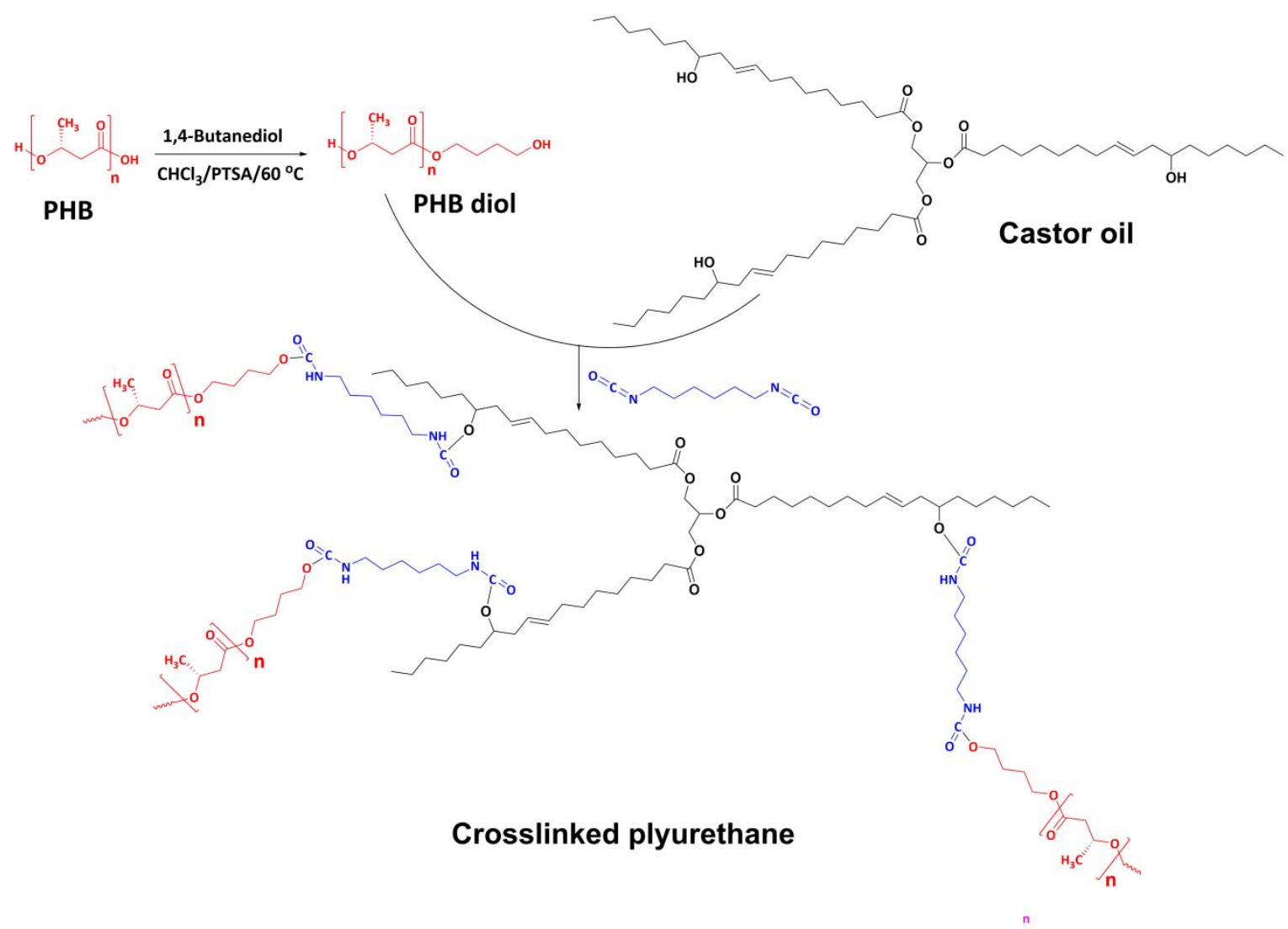

Scheme 1. Synthesis route of PUs.

\subsection{Characterization}

FTIR spectra were carried out between 400 and $4000 \mathrm{~cm}^{-1}$ using a Perkin-Elmer B25 spectrophotometer. Calorimetric measurements were carried out using a TA Instruments Co. Q20 Differential Scanning Calorimeter (DSC; USA). Thermal degradation studies were conducted using a Shimadzu TGA-50H Thermal Analyzer. SEM images of were obtained by a JOEL JXA-840 scanning electron microscope. Wide-angle X-ray diffraction (WAXD) measurements were performed at room temperature using a Philips Xpert MPD Pro diffractometer.

\subsection{Swelling}

The equilibrium swelling is given by the following equation:

Equilibrium swelling $(\%)=\frac{\mathrm{w}_{\infty}-\mathrm{w}_{0}}{\mathrm{w}_{0}} \times 100$

where $w_{\infty}$ is the sample weight at equilibrium swelling and $w_{0}$ is the initial weight of the dried sample. 


\section{Results and discussion}

\subsection{Fourier transform infrared spectroscopy (FTIR)}

Fig. 1 shows the FTIR analysis for CO, PHB-diol, U(PHB/CO)-20 and U(PHB/CO)-40. $\mathrm{CO}$ exhibits a broad band around $3413 \mathrm{~cm}^{-1}$ for the $\mathrm{O}-\mathrm{H}$ group, small band at $3009 \mathrm{~cm}^{-1}$ for sp $\mathrm{C}-\mathrm{H}$, two bands at $2919 \mathrm{~cm}^{-1}$ and $2855 \mathrm{~cm}^{-1}$ which are assigned to the asymmetric and symmetric $\mathrm{C}-\mathrm{H}$ stretching modes, respectively. The carbonyl of the ester group is appeared at $1744 \mathrm{~cm}^{-1}$. PHB diol exhibits two bands at $3443 \mathrm{~cm}^{-1}$ and $3530 \mathrm{~cm}^{-1}$ for stretching vibrations of the primary and secondary $\mathrm{OH}$ terminal groups, respectively. A strong band for $\mathrm{C}=\mathrm{O}$ stretching is observed at $1720 \mathrm{~cm}^{-1}$. For PUs, the band of hydroxyl group was disappeared, and new bands appeared of -NH stretching vibration of urethane groups at $3340 \mathrm{~cm}^{-1}$.

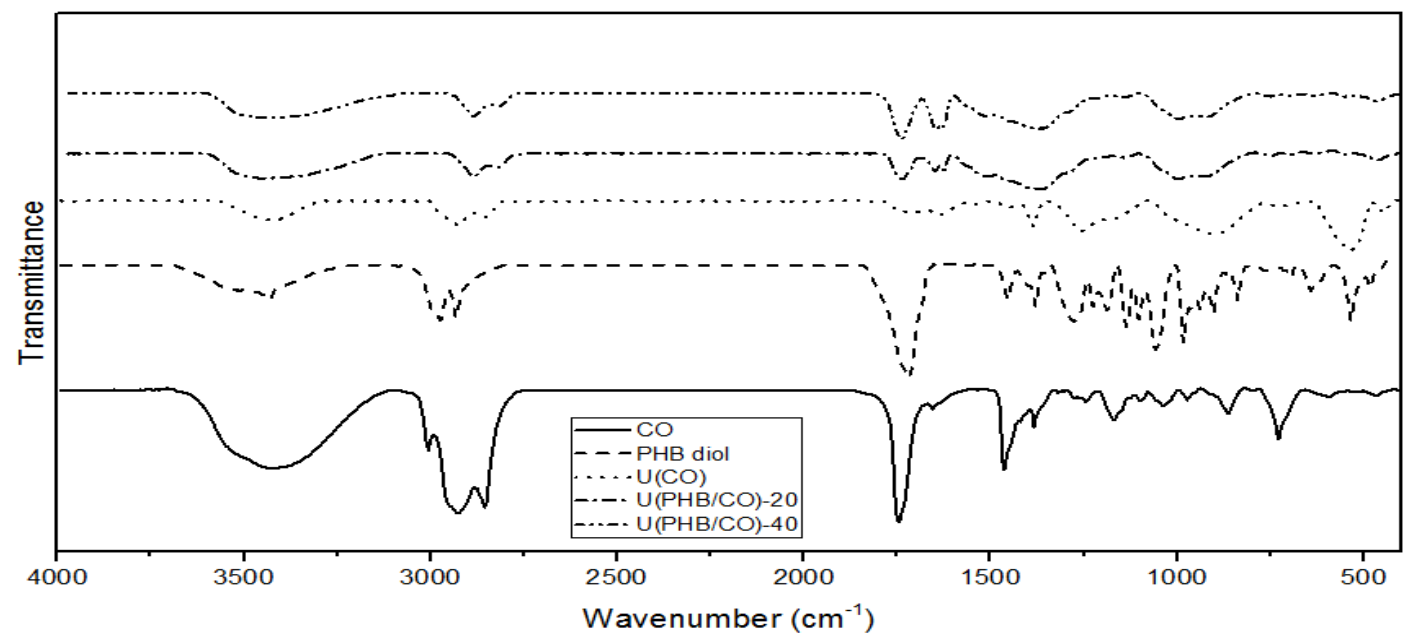

Fig. 1.FTIR of PHB diol, CO and their PUs

\subsection{Scanning electron microscopy (SEM)}

Examination the morphology through SEM (Fig. 2) shows that the fracture surface of the PUs sample based on $\mathrm{CO}$ is smooth and continuous. The surface roughness increased with the introduction of PHB and C25A.

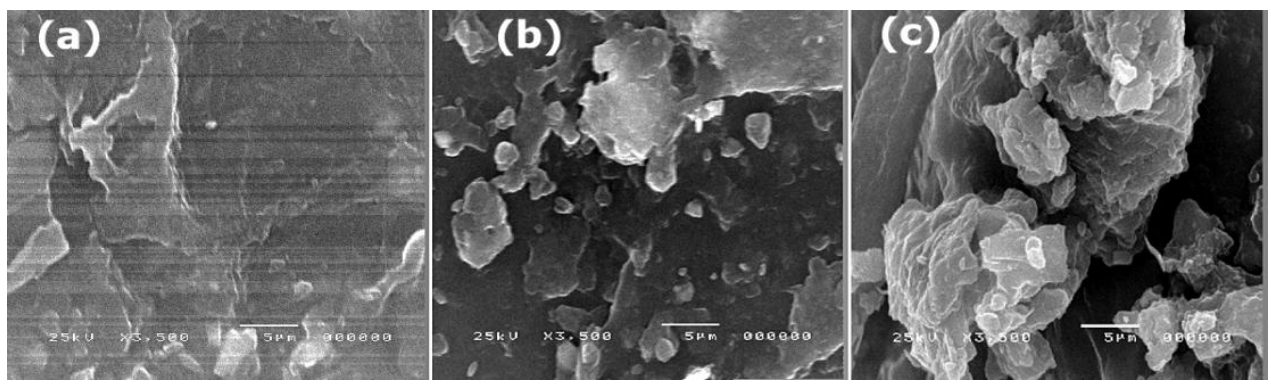

Fig 2. SEM images of (a) U(CO), (b) U(PHB/CO)-20 and (c) U(PHB/CO)-20-7C. 


\subsection{Differential scanning calorimetry (DSC)}

Fig. 3 shows DSC curves obtained for the synthesized PUs with various PHB contents. The glass transition temperatures $\left(T_{\mathrm{g}}\right)$, cold crystallization temperature $\left(T_{\mathrm{cc}}\right)$, enthalpy of cold crystallization $\left(\Delta H_{\mathrm{cc}}\right)$, melting temperature $\left(T_{\mathrm{m}}\right)$, enthalpy of melting $\left(\Delta H_{\mathrm{m}}\right)$, melt crystallization temperatures $\left(T_{\mathrm{mc}}\right)$ and enthalpy of melt crystallization $\left(\Delta H_{\mathrm{mc}}\right)$ derived from these curves are listed in Table 2. It is obvious that the PU sample based only on CO is amorphous, while PUs based on both PHB and CO are semi-crystalline. As can be seen from Fig. 3a, (Run 1), the CO soft segments show a $T_{\mathrm{g}}$ at $-42{ }^{\circ} \mathrm{C}$, which decreases as the PHB content increases. For PUs based on PHB and CO, a double melting transition appears between $140-170^{\circ} \mathrm{C}$. Neither $T_{\mathrm{g}}$ or cold crystallization $\left(T_{\mathrm{cc}}\right)$ transitions related to PHB segments are detected in these thermograms. The DSC curves after rapid cooling (Run II) of PUs based on PHB and CO, as shown in Fig. 3b, display several thermal transitions. The $\mathrm{CO}$ phase shows a $T_{\mathrm{g} 1}$ at low temperature, which is higher than the value measured for pure polyol $\left(T_{\mathrm{g}}=-63.0^{\circ} \mathrm{C}\right)$, while the $T_{\mathrm{g} 2}$ of the PHB phase appears at around $1.8{ }^{\circ} \mathrm{C}$, which is higher than pure PHB-diol $\left(T_{\mathrm{g}}=-4.8^{\circ} \mathrm{C}\right)$. As expected, increasing PHB content leads to increasing the value of $T_{\mathrm{g} 1}$. On the other hand, $T_{\mathrm{g}}$ of PHB remains nearly constant and independent on the composition of PUs. Above $T_{\mathrm{g} 2}$, exotherm cold crystallization temperature $\left(T_{\mathrm{cc}}\right)$ is observed followed by a double melting peaks corresponding to crystallization and melting of $\mathrm{PHB}$ phase, respectively. Moreover, the $T_{\mathrm{cc}}$ shifts to lowertemperature while the cold crystallization enthalpy, $\Delta H_{\mathrm{cc}}$, increases as the PHB content increases. it is seen (Fig. 3c), thatthe PUs exhibit melt crystallization peaks corresponding to crystallization of PHB segments. However, as the PHB content increases, the melt crystallization peak becomes broad and shifts to higher temperature. The degree of crystallinity of PHB in the PUs can be determined from the following equation:

$\chi_{\mathrm{c}}=\frac{\Delta \mathrm{H}_{\mathrm{m}}}{\mathrm{w} \cdot \Delta \mathrm{H}_{\mathrm{m}}^{\mathrm{o}}} \times 100$

where $\Delta H_{m}$ is the enthalpy of melting; $\Delta H_{m}^{o}$ refers to the enthalpy of $100 \%$ crystalline PHB, which was set as $143 \mathrm{~J} / \mathrm{g}$ (Brandrup, Immergut et al. 12005), and $w$ is the weight fraction of PHB component.The calculated crystallinity of $\mathrm{PHB}$ in the $\mathrm{U}(\mathrm{PHB} / \mathrm{CO})-20, \mathrm{U}(\mathrm{PHB} / \mathrm{CO})-40$ and $\mathrm{U}(\mathrm{PHB} / \mathrm{CO})-60$ were $24.3 \%, 29.5 \%$ and $40.2 \%$, respectively. 
Table 2Thermal transitions of the synthesized PUs and their nanocomposites.

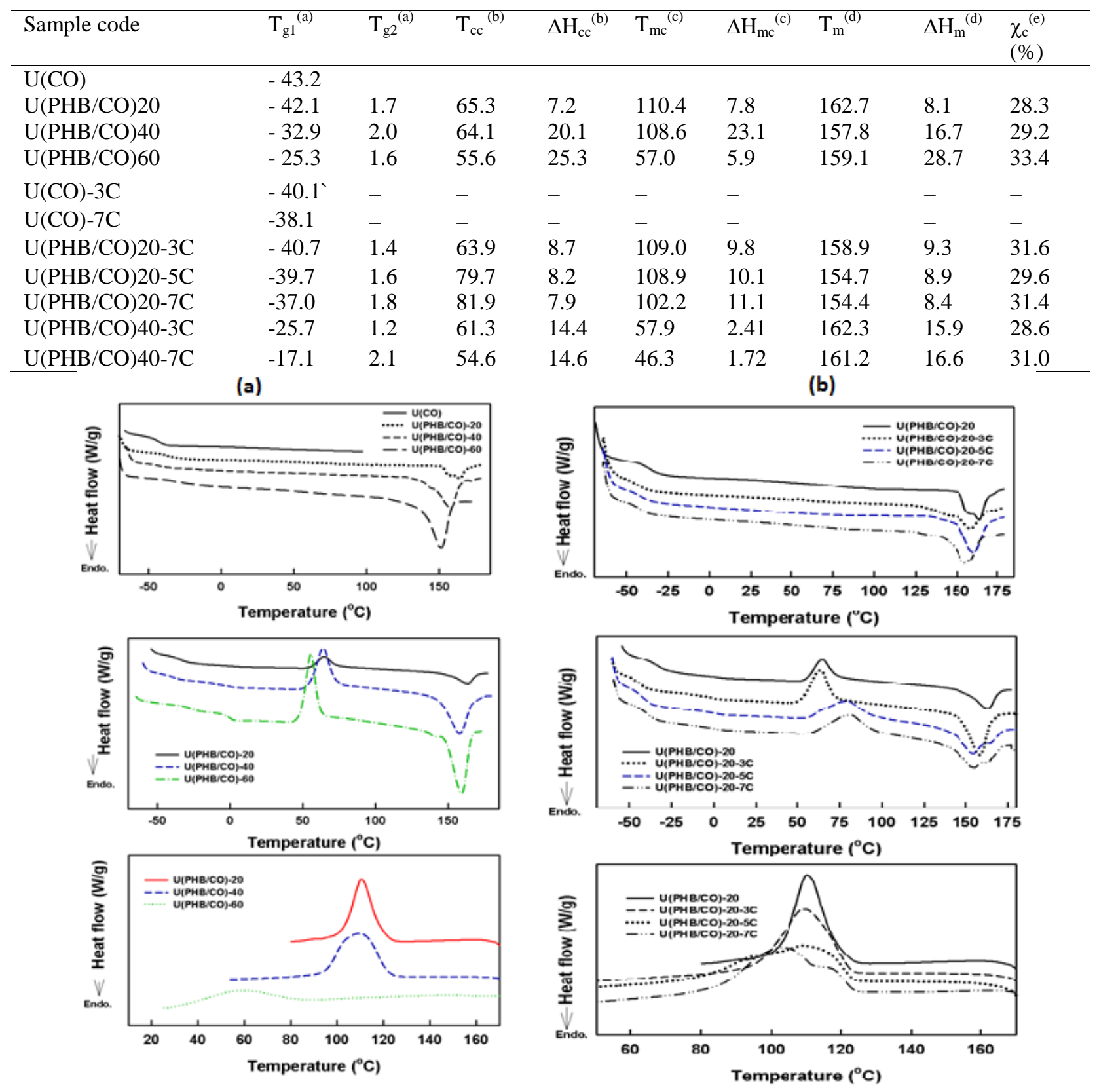

Fig. 3.(a) DSC curves of the PUs based on PHB and CO,(b) DSC curves of the U(PHB/CO)-20 and its nanocomposites.

Fig. (3b)reveals thatthe $T_{\mathrm{g} 1}$ of $\mathrm{CO}$ phase slightly shifts to lower temperature with increasing $\mathrm{C} 25 \mathrm{~A}$ content, while the $T_{\mathrm{g} 2}$ related to the PHB phase does not significantly affect. Fig. $4 \mathrm{~b}$ and Table 2reveals that the cold crystallization of PHB shifts to higher temperature with 
increasing the C25A. In the cooling run (Fig. 3b), it is observed that the peak tends to separate into two peaks with increasing the $\mathrm{C} 25 \mathrm{~A}$ content up to $7 \mathrm{wt} \%$.

\subsection{X-ray diffraction}

Fig.5 shows the X-ray diffraction curves of some selected samples along with C25A as an inset graph. The $\mathrm{U}(\mathrm{CO})$ sample exhibits a broad peak at $18.7^{\circ}$, indicating some degree of ordering. For PUs samples containing 20.0 and 40.0\% PHB, two strong diffraction peaks related to crystallite of the PHB segments are observed around $2 \theta=513.6^{\circ}$ and $17.1^{\circ}$. On comparing the diffraction pattern of $\mathrm{U}(\mathrm{PHB} / \mathrm{CO})-20$ with its nanocomposite, no change in the diffraction peaks of $\mathrm{PHB}$ is observed. Moreover, the characteristic peak for $\mathrm{C} 25 \mathrm{~A}$ at $4.6^{\mathrm{O}}$ isnot detected in $\mathrm{U}(\mathrm{PHB} / \mathrm{CO}) 20-7 \mathrm{C}$ sample.

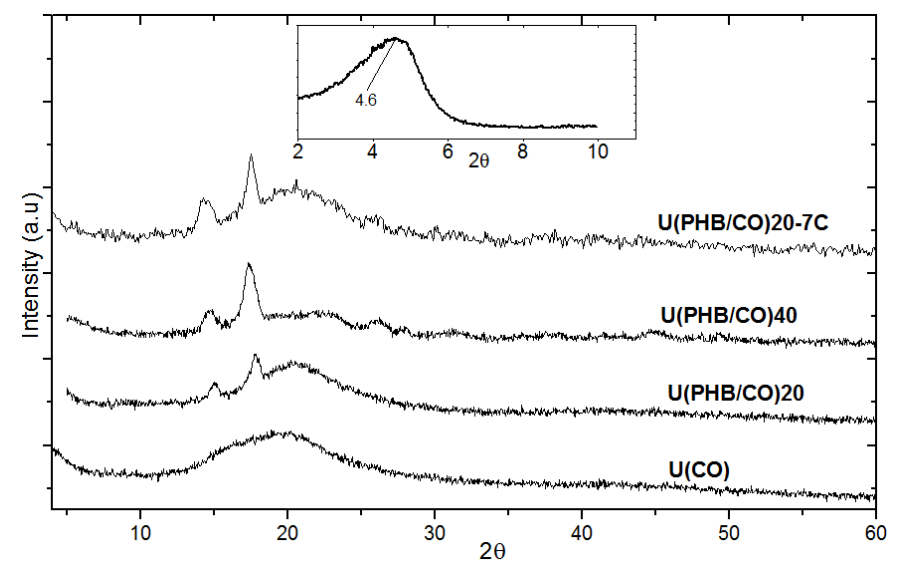

Fig. 5. WAXD patterns of $\mathrm{U}(\mathrm{CO}), \mathrm{U}(\mathrm{PHB} / \mathrm{CO})-20, \mathrm{U}(\mathrm{PHB} / \mathrm{CO})-40, \mathrm{U}(\mathrm{PHB} / \mathrm{CO})-20-7 \mathrm{C}$ and C25A (inset graph).

\subsection{Thermogravimetric analysis (TGA)}

The TGA and DTG curves for $\mathrm{U}(\mathrm{CO})$ and $\mathrm{U}(\mathrm{PHB} / \mathrm{CO})$ containing different amounts of PHB are displayed in Fig. 6(a).As shown, the thermal degradation of all PUs occurs mainly in a three-stage process(Chattopadhyay and Webster 2009). The thermal stability parameters including, the onset decomposition temperature, which is defined as the temperature at $5 \%$ mass loss $\left(T_{0.5}\right)$, the peak temperatures of the first degraded stage $\left(T_{1 \max }\right)$, the second stage $\left(T_{2 \max }\right)$ and the third degradation $\left(T_{3 \max }\right)$ are given in Table 3.For PUs based only on castor oil $\mathrm{U}(\mathrm{CO})$, the first degradation step is observed around $290^{\circ} \mathrm{C}$ with main decomposition rate at $313^{\circ} \mathrm{Cand}$ is related to the thermal decomposition of unstableurethane bonds (Luo, Mohanty et al. 2013). The second step occurs above $320^{\circ} \mathrm{C}$ with main degradation rate at $35^{\circ} \mathrm{C}$ is associated with the decomposition of $\mathrm{CO}$ (Chattopadhyay and Webster 2009). The third step occurs above $410^{\circ} \mathrm{C}$ is 
related to the decomposition of the network structure of CO.For PUs based on PHB and CO segments, the decomposition of the first step shifts to lower temperature and presents a higher mass loss compared with $\mathrm{U}(\mathrm{CO})$. This step is mainly due to the degradation of the PHB segments, as a consequence of its relatively low thermal stability. The second and third stages correspond to the thermal decomposition of the CO soft segments.As shownTable 3 and Fig. 6(b), the thermal stability of the PUs is improved by incorporation of C25A in copolymer matrix.

(a)
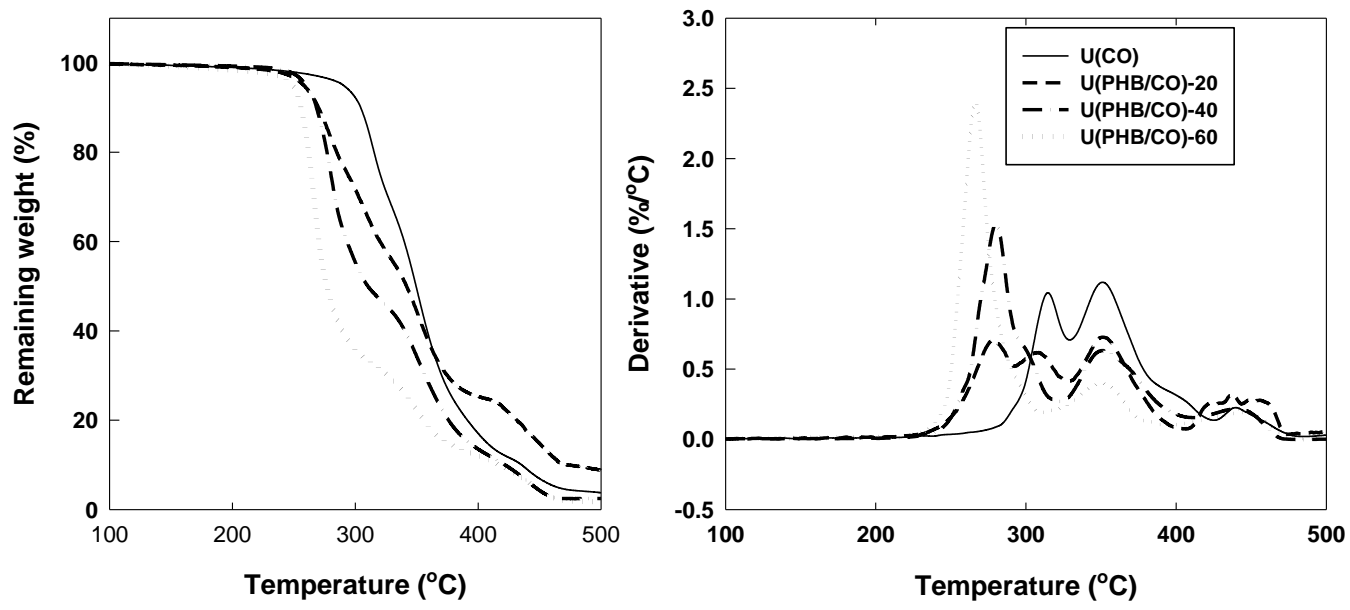

(b)
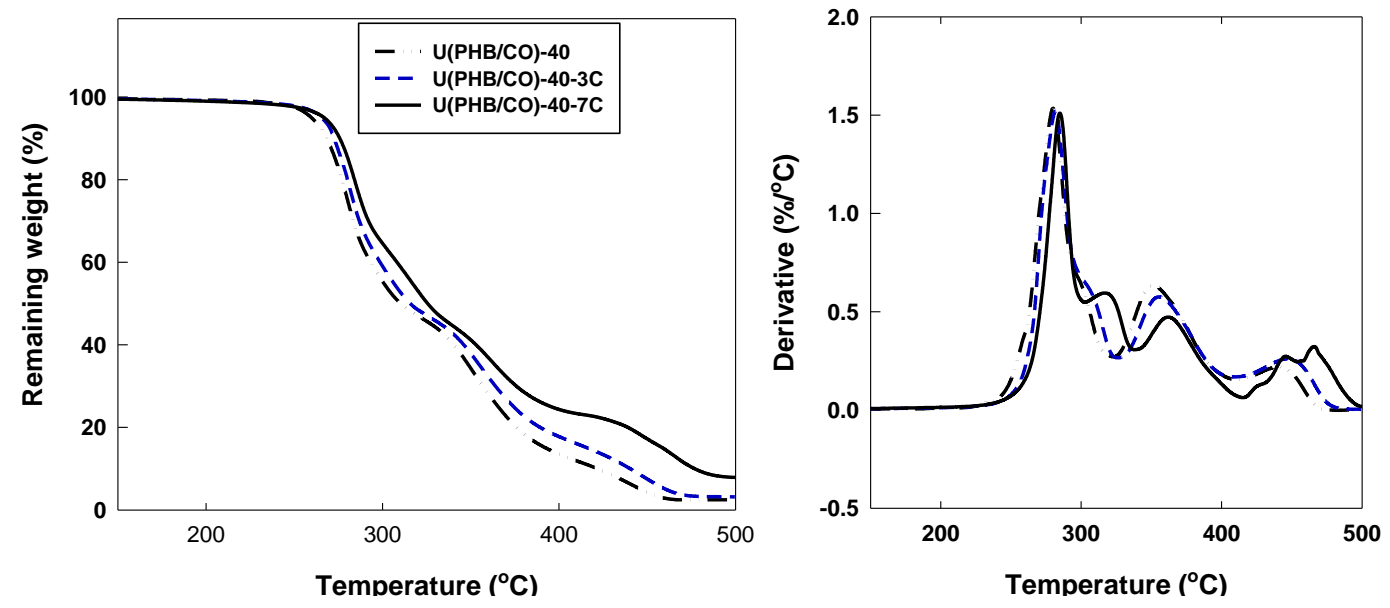

Fig. 6.(a) TGA and DTG curves for PUs and U(PHB/CO)-40 nanocomposites.

Table3 Thermal parameters of synthesized PUs and their nanocomposites.

\begin{tabular}{llllll}
\hline Sample code & $\mathrm{T}_{0.5}\left({ }^{\circ} \mathrm{C}\right)$ & $\mathrm{T}_{1 \max }\left({ }^{\circ} \mathrm{C}\right)$ & $\mathrm{T}_{2 \max }\left({ }^{\circ} \mathrm{C}\right)$ & $\mathrm{T}_{3 \max }\left({ }^{\circ} \mathrm{C}\right)$ & Char yield $(\%)$ \\
\hline $\mathrm{U}(\mathrm{CO})$ & 290 & 313 & 351 & 440 & 3.8 \\
$\mathrm{U}(\mathrm{PHB} / \mathrm{CO}) 20$ & 258 & 277 & 351 & 436 & 8.8 \\
$\mathrm{U}(\mathrm{PHB} / \mathrm{CO}) 20-3 \mathrm{C}$ & 269 & 280 & 353 & 439 & 8.2 \\
$\mathrm{U}(\mathrm{PHB} / \mathrm{CO}) 20-7 \mathrm{C}$ & 278 & 284 & 360 & 448 & 8.6 \\
$\mathrm{U}(\mathrm{PHB} / \mathrm{CO}) 60$ & 249 & 266.6 & 350 & 446 & 1.8 \\
\hline
\end{tabular}




\subsection{Equilibrium swelling}

It is shown fromFig. 8that increasing the amount of PHB in the PUs decreases the swelling degree. Furthermore, the swelling is found to be decreased upon increasing C25A content.

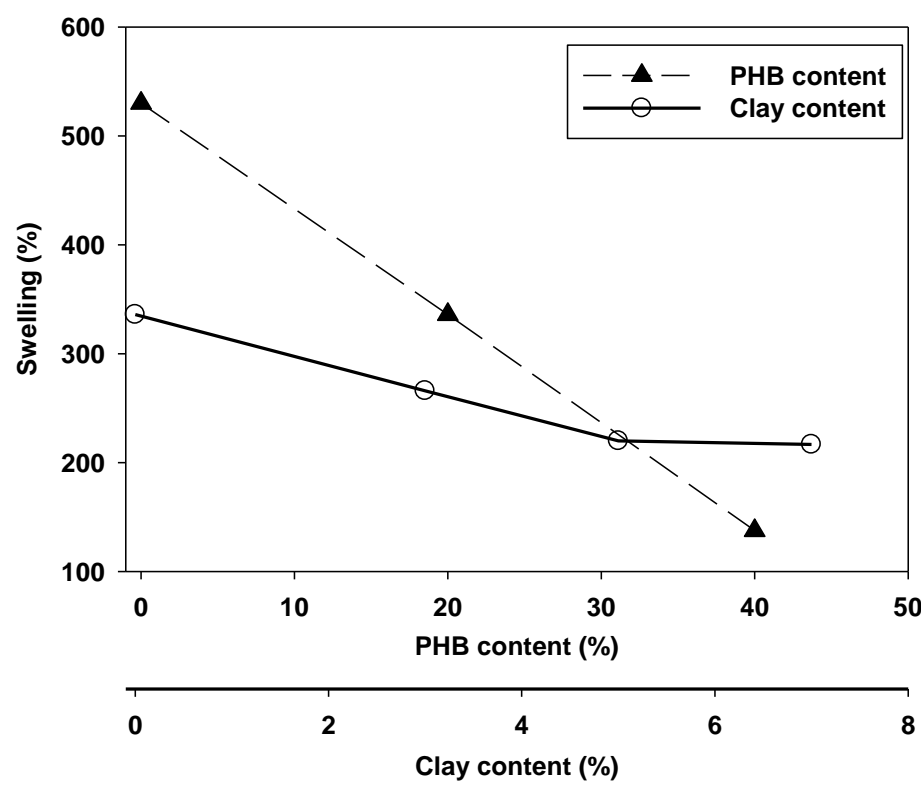

Fig. 8. Effect of the PHB content (black plot) and C25A content (red plot) on the equilibrium swelling.

\section{Conclusions}

Series of PUs based on PHB and CO were successfully prepared using HDI as coupling agent and dibutyltin dilaurate as a catalyst. FTIR confirmed the formation of PUs. Nanocomposites of the prepared PUs with C25A were also prepared which showed an improved thermal stability compared with the neat PUs. SEM showed that the surface roughness increases with increasing both PHB and C25A. Swelling studies showed that the equilibrium swelling was decreased with increasing the PHB and C25A contents. DSC showed that PUs possess two glass transition while the $T_{\mathrm{g}}$ of $\mathrm{CO}$ was shifted to higher temperature with increasing the PHB. $T_{\mathrm{m}}$ of PHB segment was shifted to higher temperature with increasing the PHB, and to lower ones with increasing $\mathrm{C} 25 \mathrm{~A}$. TGA showed that the thermal stability was decreased with increasing the PHB content, and increased with increasing the C25A. 


\section{References}

Abdel Aziz, M. S., et al. (2014). "Preparation and characterization of biodegradable polyurethane nanocomposites based on poly (3-hydroxybutyrate) and poly (butylene adipate) using reactive organoclay." Polymer-Plastics Technology and Engineering53(16): 1671-1681.

Aziz, M. S. A., et al. (2015). "Non-isothermal crystallization kinetics of poly (3hydroxybutyrate) in copoly (ester-urethane) nanocomposites based on poly (3-hydroxybutyrate) and cloisite 30B." Thermochimica Acta605: 52-62.

Brandrup, J., et al. (12005). Polymer handbook, Wiley New York etc.

Chattopadhyay, D. and D. C. Webster (2009). "Thermal stability and flame retardancy of polyurethanes." Progress in Polymer Science34(10): 1068-1133.

Kaushik, A., et al. (2011). "Synthesis and characterization of organically modified clay/castor oil based chain extended polyurethane nanocomposites." Composites Part A: Applied Science and Manufacturing42(10): 1534-1541.

Luo, X., et al. (2013). "Lignin as a reactive reinforcing filler for water-blown rigid biofoam composites from soy oil-based polyurethane." Industrial Crops and Products47: 13-19.

Naguib, H. F., et al. (2011). "Synthesis and thermal characterization of poly (ester-ether urethane) s based on PHB and PCL-PEG-PCL blocks." Journal of Polymer Research18(5): 12171227.

Panda, S. S., et al. (2017). "Preparation, characterization, and properties of castor oil-based flexible polyurethane/Cloisite 30B nanocomposites foam." Journal of Composite Materials: 0021998317710707.

Reeve, M. S., et al. (1993). "Preparation and characterization of (R)-poly (. beta.hydroxybutyrate)-poly (. epsilon.-caprolactone) and (R)-poly (. beta.-hydroxybutyrate)-poly (lactide) degradable diblock copolymers." Macromolecules 26(5): 888-894. 